\title{
Intestinal Glycolipids and Their Possible Role in Microbial Colonization of Mice
}

\author{
Yoshinori UMESAKI \\ Yakult Central Institute for Microbiological Research, \\ Yaho 1796, Kunitachi, Tokyo, 186 \\ (Received for publication, November 9, 1988)
}

Key words: intestine; glycolipid; germfree animal; microbial colonization; bacterial attachment

The alimentary tract is colonized by more than one hundred species of and more than one thousand billion microbes (per gram contents). It is well known that the microbes colonized characteristically according to the site of the alimentary tract and species and physiological conditions of the host animal such as age (16, 17, 19). Comparative studies between germfree and conventional animals clearly show that the intestinal microbes greatly affect physiology and morphology of the intestine of the host animal. However, we have not yet been able to obtain precise mechanisms of the difference between germfree and conventional animals in spite of great efforts thus far.

On the other hand, the sphingoglycolipids are now studied from the aspect of the host receptor-intestinal microbe interaction. The glycolipids are very abundant in the microvillus membrane of the small intestinal epithelial cells $(11,14)$. The composition of these glycolipids are different among species (3), developmental ages of the animals $(12,18)$, and between normal and pathological conditions of the host animals $(6,9)$. And also these glycolipids have, at least in vitro, high affinity for the microbes $(10)$ as well as the enterotoxins produced by pathogenic microorganisms (27). Thus there is some reason to consider that the glycolipid might be a mediator between host animals and intestinal microbes.

In this review, we summarize what changes occur in the intestinal glycolipids by association of the intestinal microbes with germfree animals, discuss the mechanism of this glycolipid change, and finally consider what roles these glycolipids play in the colonization of the intestinal microbes.

\section{THE GLYCOLIPIDS OF THE SMALL INTESTINAL EPITHELIAL CELLS IN MICE}

The glycolipids present in the mammals are, generally, sphingoglycolipids. The sphingoglycolipids are usually divided into neutral glycolipids and acidic glycolipids such as gangliosides and sulfatides. Table 1 summarizes the structures of glycolipids present in the small and the large intestine of mice. Glucosyl ceram- 
Table 1. Structures of intestinal glycolipids in mice

\begin{tabular}{|c|c|c|c|}
\hline Glycolipids & Carbohydrate structure & Expression period & References \\
\hline \multicolumn{4}{|l|}{ Neutral glycolipids } \\
\hline Glucosyl ceramide & Glc-Cer & throughout life & $(18,21)$ \\
\hline Asialo GM1 & $\mathrm{Gal} \beta 1-3 \beta \mathrm{GalNAc} \beta 1-4 \mathrm{Gal} \beta 1-4 \mathrm{Glc}-\mathrm{Cer}$ & after weaning & $(21)$ \\
\hline Fucosyl asialo GM1 & $\begin{array}{l}\text { Fuc } \alpha 1-2 \mathrm{Gal} \beta 1-3 \beta \mathrm{GalNAc} \beta 1-4 \mathrm{Gal} \beta 1- \\
\quad 4 \mathrm{Glc}-\mathrm{Cer}\end{array}$ & at weaning 1 ) & (23) \\
\hline \multicolumn{4}{|l|}{ Gangliosides } \\
\hline GM3 & Neu $\alpha 2-3 \mathrm{Gal} \beta 1-4 \mathrm{Glc}-\mathrm{Cer}$ & before weaning & $(18)$ \\
\hline GM1 & $\begin{array}{l}\text { Gal } \beta 1-3 \mathrm{GalNAc} \beta 1-4(\mathrm{Neu} \alpha 2-3) \mathrm{Gal} \beta 1- \\
\quad 4 \mathrm{Glc}-\mathrm{Cer}\end{array}$ & before weaning & $(18)$ \\
\hline GDla & $\begin{array}{l}\text { Neu } \alpha 2-3 \mathrm{Gal} \beta 1-3 \mathrm{GalNAc} \beta 1-4(\mathrm{Neu} \alpha 2-3) \\
\quad \text { Gal } \beta 1-4 \mathrm{Glc}-\mathrm{Cer}\end{array}$ & before weaning & $(18)$ \\
\hline \multicolumn{4}{|l|}{ Sulfatide } \\
\hline Sulfo-asialo GM1 & $\begin{array}{l}\mathrm{HSO}_{3}-2 \mathrm{Gal} \beta 1-3 \mathrm{GalNAc} \beta 1-4 \mathrm{Gal} \beta 1- \\
\quad 4 \mathrm{Glc}-\mathrm{Cer}\end{array}$ & adult mice & $(15)$ \\
\hline
\end{tabular}

ide and asialo GM1 were major components after birth and weaning, respectively $(18,21)$. Fucosyl asilo GM1 was expressed during the weaning stage, and thereafter present as a minor component $(18,22,23)$. GM3, GM1, GDla were major glycolipids before weaning (18). $\mathrm{HSO}_{3}$-asialo $\mathrm{GMl}$ was a major component in acidic glycolipids in adult mice (10). The amount of neutral glycolipids exceed the acidic glycolipids after the weaning stage. The glycolipid composition of other species are described in detail elsewhere (3). The composition of the glycolipids are very characteristic among species of animals. Strain-specificity in intestinal glycolipid composition of rat was reported (3), although its difference is not known in mice. In humans, the diversity of glycolipids are present among individuals according to the blood type and secretor phenotype (1).

The ceramides, the hydrophobic portion of glycolipids, in the intestine have $\alpha$ hydroxy fatty acids in combination with phytosphingosine (21). Therefore, the glycolipids of the intestinal epithelial cells are very hydrophilic compared to the those of other organs. It is also shown that this hydrophilic structure affects binding ability of the microbes to glycolipids in vitro (7).

\section{THE DISTRIBUTION OF GLYCOLIPIDS IN THE SMALL INTESTINAL EPITHELIAL CELLS}

The distribution of the intestinal glycolipids of mice and rat are reported in detail by biochemical and histochemical methods. These glycolipids are distributed in epithelial cells from crypt bottom to the villus tip (4, 24). Glucosyl ceramide and GM3 are more abundant in villus than in crypt portion in rat (2). Immediately after conventionalization, fucosyl asilo GMl was more strongly expressed in villous cells than in crypt in mice. Subcellular distribution of glycolipids show enrichment of glycolipids in microvillus membrane, facing the lumen of the 
intestine (24).

There is clear difference in glycolipid composition between lamina propria cells and the epithelial cells, reflecting the ontogenic difference of the two tissues $(8,20,22)$.

\section{THE DIFFERENCE OF GLYCOLIPID COMPONENTS BETWEEN GERMFREE AND CONVENTIONAL ANIMALS}

Comparative study of glycolipid composition between germfree and conventional mice has been done. A small amount of fucosyl asialo GMl is present only in conventional adult mice (25). Incorporation of radiolabeled fucose into glycolipid fraction was not detected at all in germfree counterparts. Immediately after conventionalization of germfree mice by introduction of fecal suspension of conventional mice, an abrupt increase in fucosyl asialo GMl content occurred corresponding to the induction of GDP-fucose: asialo GM1 $\alpha(1-2)$ fucosyltransferase (FT) activity as shown in Fig. 1 (26). About two weeks after conventionalization, fucosyl asialo GM1 content decreased and maintained a constant low level thereafter. There is a qualitative difference in the presence of fucosyl asialo GM1 between germfree and conventional mice. In rats, such a difference in the intestinal glycolipids has not been observed, although the time course of the conven-

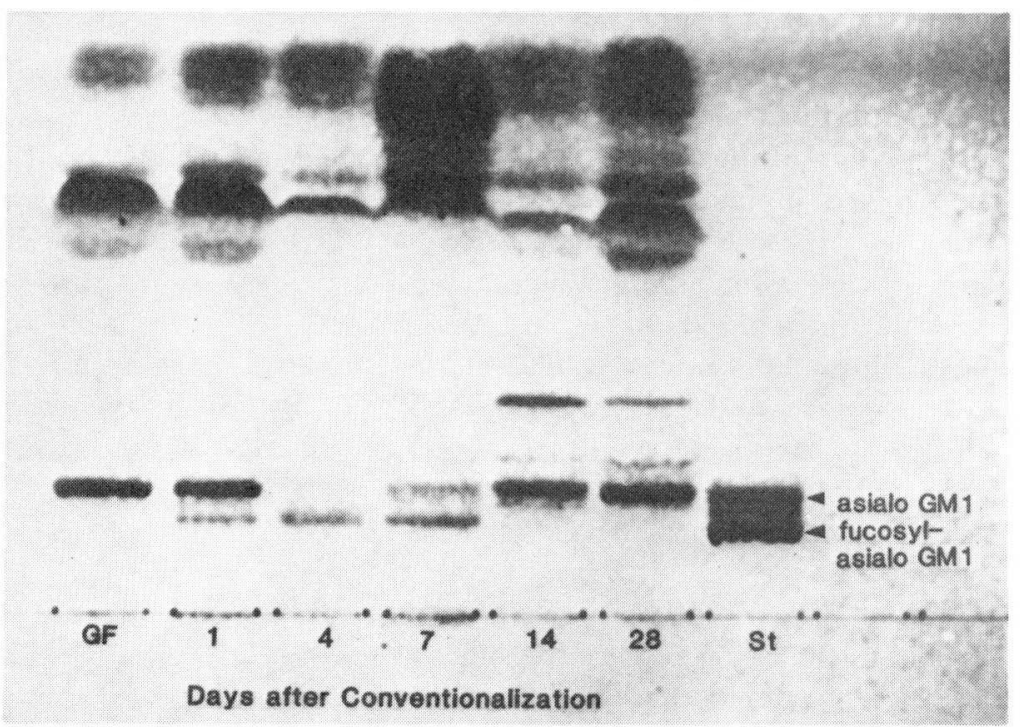

Fig. 1. A thin-layer chromatogram of the lipid fractions containing asialo GM1 and fucosyl asialo GM1. At the days after conventionalization indicated in the figure, glycolipid fractions were prepared from the mucosal homogenate $(7.0 \mathrm{mg}$ protein) as described elsewhere (26). Thin-layer chromatogram was developed with chloroform-methanol-water $(60 / 40 / 8, \mathrm{v} / \mathrm{v})$ and glycolipids were detected by spraying with $50 \%$ sulfuric acid. Lane St indicates the standard glycolipids isolated from mouse small intestine. 
tionalization process was not followed (5). In this case, the increase in $\mathrm{H}$-active glycolipid was reported in the stomach.

\section{MECHANISMS FOR ALTERATIONS OF THE GLYCOLIPID COMPOSITION BY BACTERIA}

Microbial colonization changed the glycolipid composition by the following two mechanisms. One mechanism was de novo synthesis of glycolipids. This mechanism is due to induction or activation of glycosyltransferase. The other mechanism was hydrolysis of glycolipids by glycosidases produced by intestinal microbes.

FT activity appeared by conventionalization of germfree mice as described in the previous section. It is not certain that this induction reflects de novo synthesis of glycosyltransferase. FT induction also occurred in the weaning stage of conventional mice and in some injurious treatments on the small intestine in germfree as well as conventional mice (23). The proteinaceous fraction which could induce FT activity by intravenous injection into germfree mice was obtained from the homogenate of small intestine. This fraction, although not completely, lost FTinducing activity by pronase and heat treatment. Its activity was separated into void volume fraction and M.W. 30,000-10,000 fraction on Sephadex G-200 column chromatography (unpublished data). All these facts suggest the presence of a proteinaceous factor which controls the expression of the fucoglycolipid in the mouse small intestine. This substance(s) is a candidate for a mediator of glycolipid change in the intestine.

The degradation of intestinal glycolipids was noted in humans $(12,13)$. The glycosidase involved in mucin degradation was shown to hydrolyze glycolipids. Some strains of Ruminococcus and Bifidobacterium have high glycosidase activities such as $\beta$-N-acetyl galactosaminidase, $\beta$-galactosidase, $\alpha$-fucosidase, and $\alpha$-neuraminidase. The degradation of glycolipids in the intestine is thought to be dependent on the transit time of intestinal contents. The degradation was not so clear in small animals such as mice and rats (5), probably due to fast transit of intestinal contents.

\section{GLYCOLIPIDS ALTERATION IN GNOTOBIOTES}

The intestinal glycolipids were converted from asilo GM1 into fucosyl asialo GM1 by conventionalization of germfree mice. To investigate what kind of bacteria induced this glycolipid change, FT activity was measured. As the first step, the interrelationship between the cecal bacterial composition and FT activities induced by antibiotic treatment was analyzed (Table 2). Generally, administration of antibiotics immediately after conventionalization repressed FT induction. Interrelation coefficient between the bacterial number of each genus and FT activity was estimated by analysis of variance based on the results of Table 2. Enterobacteriaceae $\left(r^{2}=0.63\right)$, Streptococci $\left(r^{2}=0.547\right)$, and Lactobacilli $\left(r^{2}=0.478\right)$ showed 
Table 2. Cecal flora and FT activity after oral administration of antibiotics

\begin{tabular}{|c|c|c|c|c|}
\hline & \multirow{2}{*}{ Control } & \multicolumn{2}{|c|}{ Gentamicin } & \multirow{2}{*}{$\frac{\text { Erythromycin }}{1.0 \mathrm{mg} / \mathrm{ml}}$} \\
\hline & & $0.5 \mathrm{mg} / \mathrm{ml}$ & $1.0 \mathrm{mg} / \mathrm{ml}$ & \\
\hline \multicolumn{5}{|l|}{ Microbes } \\
\hline Enterobacteriaceae $^{1)}$ & $8.8 \pm 0.2^{10)}$ & $4.6 \pm 0.5$ & $5.0-3.2$ & $6.0 \pm 1.0$ \\
\hline Staphylococci, Bacilli2) & 3.6 & 3.6 & 3.6 & 3.6 \\
\hline Streptococci ${ }^{3)}$ & $9.2 \pm 0.1$ & 3.6 & $4.1-1.4$ & 3.6 \\
\hline Lactobacilli4) & 8.8 & $4.5 \pm 0.5$ & $3.7-1.0$ & 3.6 \\
\hline Bacteroides ${ }^{5)}$ & $10.0 \pm 0.1$ & $9.9 \pm 0.1$ & $7.2 \pm 1.2$ & 3.6 \\
\hline Bifidobacterium $^{6}$ ) & $5.7 \pm 0.7$ & $7.3 \pm 0.4$ & $3.7 \pm 1.0$ & $3.8-1.1$ \\
\hline Pseudomonas ${ }^{7)}$ & 3.6 & 3.6 & 3.6 & $3.7-1.0$ \\
\hline Fungi, Yeast ${ }^{8)}$ & 3.6 & 3.6 & 3.6 & 3.6 \\
\hline Total bacteria 9 ) & $10.4 \pm 0.2$ & $10.0 \pm 0.2$ & $9.0 \pm 0.1$ & $9.2 \pm 0.2$ \\
\hline FT activity & $251 \pm 170^{11)}$ & $49 \pm 16$ & $35 \pm 12$ & $82 \pm 37$ \\
\hline \multicolumn{5}{|c|}{$\begin{array}{l}\text { 1, MacConkey; } 2 \text {, Mannit salt; } 3, \mathrm{SF} ; 4, \mathrm{LBS} ; 5 \text {, modified NBGT; } 6 \text {, YBS; } 7 \text {, NAC; } 8 \text {, PD; } \\
9 \text {, GAM. } \\
\text { 10) The values are logarithmic number of bacteria (mean } \pm \mathrm{SD}, n=4 \text { ) per gram cecal } \\
\text { contents. }\end{array}$} \\
\hline
\end{tabular}

Table 3. FT induction in conventionalized and gnotobiotic mice

\begin{tabular}{|c|c|c|}
\hline \multirow{2}{*}{ Mice } & \multicolumn{2}{|c|}{ Days after administration of bacteria } \\
\hline & 3 days & 7 days \\
\hline Germfree & $0.65 \pm 0.06^{5)}$ & - \\
\hline Gnotobiote $1^{1)}$ & $2.37 \pm 0.65$ & - \\
\hline Gnotobiote $2^{2)}$ & $2.27 \pm 0.92$ & $2.92 \pm 0.27$ \\
\hline Gnotobiote $3^{3)}$ & $3.22 \pm 1.25$ & - \\
\hline Conventionalized mice ${ }^{4)}$ & $132 \pm 48$ & $87.5 \pm 22$ \\
\hline
\end{tabular}
stomach.

2) The mixture of suspension of E. coli, 2 strains (one strain was the same as in gnotobiote 1 group), and Proteus sp. was administered.

3) The mixture of L. acidophilus, L. fermentum, L. murini, S. faecalis, and two species each of Bifidobacterium and Bacteroides, in addition to the same three stains of gnotobiote 2 group, was administered.

4) The mice were transferred from isolator to open air, and the fecal suspension was administered.

5) Enzyme activity was expressed as $\mathrm{pmol} / \mathrm{mg}$ protein $/ \mathrm{min}(n=5)$.

high coefficients. Coefficients of Bifidobacterium $\left(r^{2}=0.046\right)$, Bacteroides $\left(r^{2}=0.033\right)$, and other genera $\left(r^{2}=0\right)$ were very low. Based on these results, three kinds of gnotobiotes were prepared (Table 3). A little elevation of FT activity was observed in these gnotobiotes. However, the values were extremely low compared to those of the conventional mice group. There was little difference in FT activity between $E$. coli mono-contaminated mice and multi-contaminated mice.

As $E$. coli showed some affinity to asialo GM1-coated plastic plate as described 


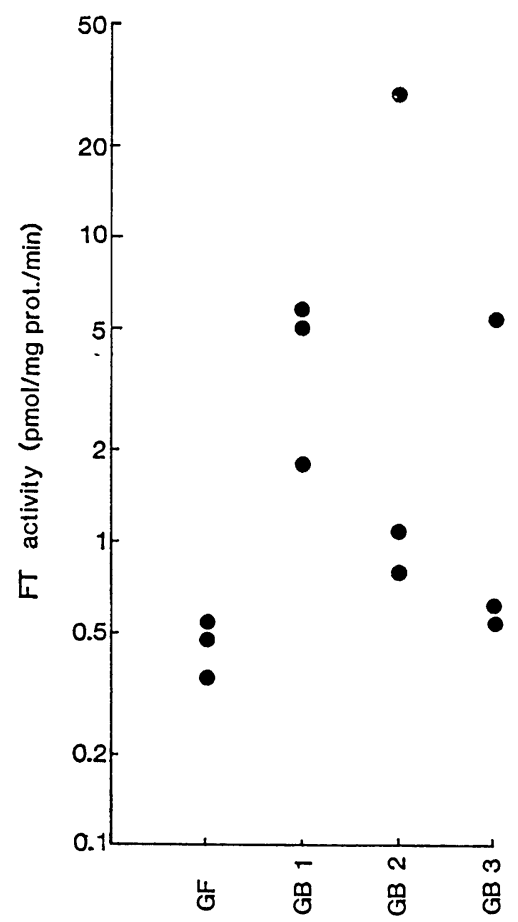

Fig. 2. FT induction in the gnotobiotic mice contaminated with E. coli. E. coli was isolated from asialo GMI-adherent experiment as shown in Fig. 3 (GB 2). In comparison, $E$. coli was directly isolated from cecal contents of mouse (GB 1) and rat (GB 3) using MacConkey agar plate. GF shows the germfree mice.

in the next section, we tried to make some kinds of gnotobiotes associated with $E$. coli isolated from adhesion experiment. There is still great difference in FT activity induction between conventionalized mice and gnotobiotic mice associated with $E$. coli showing some affinity to asialo GMl-coated plastic plate, although some gnotobiote induced FT activity to near the level of conventionalized mice (Fig. 2).

\section{THE INTESTINAL GLYCOLIPIDS AS ATTACHMENT SITE FOR BACTERIA}

The functions of intestinal glycolipids are obscure, except that they are known to be the receptors of enterotoxins. However, it has been clear that some neutral glycolipids show high affinity to bacterial cells in in vitro experiment using glycolipidcoated plastic plate or thin-layer plate. We investigated the extent to which alteration of glycolipids affects affinity of bacterial cells to the intestinal cell surface glycolipids in vitro using glycolipid-coated plastic plate. Figure 3 is a diagram of this method. An especially large number of bacteria in Enterobacteriaceae were recovered from asilo GM1-coated plastic plate at one dilution rate of bacterial suspension, as shown in Fig. 4. Recovery of bacteria of other genera were very low compared to 


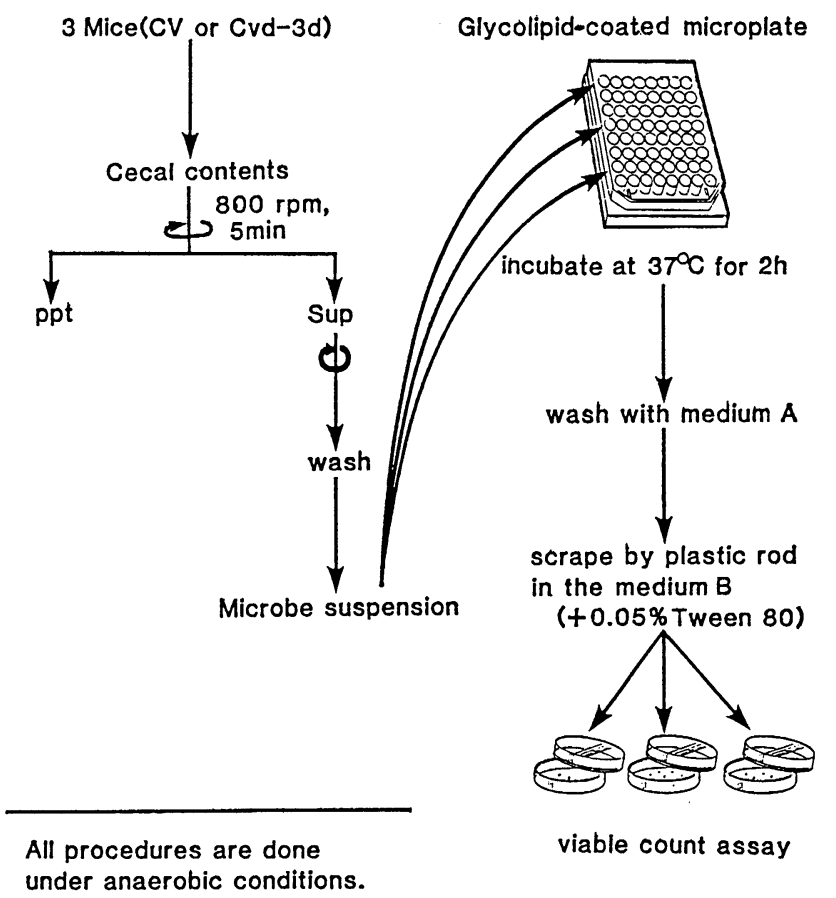

Fig. 3. Schematic presentation of bacterial adhesion test using a glycolipid-coated plastic plate. The cecal contents of conventionalized mice for 3 days were suspended, briefly spun, and the supernatant was obtained. This supernatant was centrifuged again at high speed $(10,000 \mathrm{rpm}, 30 \mathrm{~min})$ and washed with saline. Bacterial suspension was prepared at 10 times concentration of original cecal supernatant. The bacterial suspensions serially diluted were overlaid in the wells of a microplate which was previously coated with glycolipid. After incubation at $37^{\circ} \mathrm{C}$ for $2 \mathrm{hr}$, the plate was gently rinsed with medium A (saline), and finally the microbes were scraped with medium B $(0.05 \%$ Tween 80 in saline) using a plastic rod. The microbes of this suspension thus obtained were analyzed in various kinds of selective media as shown in Table 2.

Enterobacteriaceae. On the other hand, of all genera tested, no bacteria was recovered from fucosyl asialo GM1-coated plastic plate. It is not known why many bacteria were recovered from the ceramide (hydrophobic portion of glycolipids)-coated plate. The bacterial compositions recovered from asialo GM1- and fucosyl asialo GM1coated plastic plate are shown as percentages in Fig. 5. This result suggests a possibility that fucosylation of asilo GM1 glycolipid represses the adhesion of Enterobacteriaceae, which is superior in number just after conventionalization of mice, to host cells. The possibility of a defense mechanism by alteration of sugar structures of the membrane needs further investigation.

Other glycolipids present in humans, rats, etc. have been tested for bacterial binding (10). In these studies, glycolipids were developed on thin-layer plate, radiolabeled bacterial cell suspensions were overlaid on the plate, and finally the binding was detected by radioautography. Propionibacterium and E. coli (patho- 

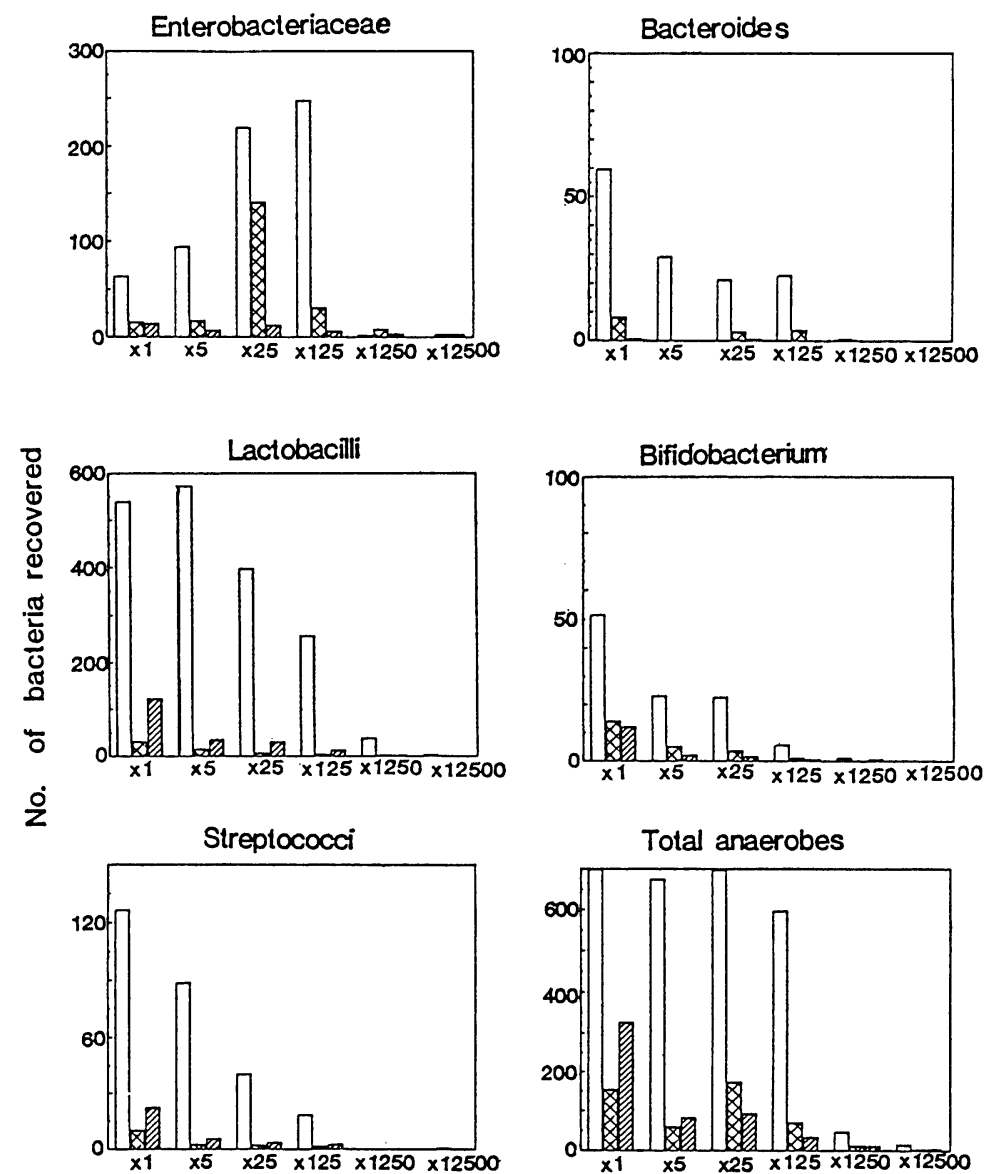

Fig. 4. Bacterial adhesion to the glycolipid-coated plastic microplate. Microbe suspensions serially diluted (5 times) were overlaid in the glycolipid-coated plate. After washing with phosphate-buffered saline, the residual number of each bacteria was counted in each selective medium, respectively. $0.5 \mu \mathrm{g}$ of asialo GMI glycolipid (crossed bar), fucosyl asialo GM1 (hatched bar), or ceramide (open bar) was previously coated in a 96-well plastic plate. The figures in the abscissa indicate the dilution rate of the microbe suspension. The method for bacterial adhesion is illustrated in Fig. 3. The viable number of each bacteria was counted as shown in Table 2.

genic) are shown to strongly bind to some glycolipids on thin-layer plate. Especially, lactosyl ceramide, present in human feces (13) and the rat (5), was recognized by many kinds of bacteria.

\section{CONCLUDING REMARKS}

The intestinal glycolipids are closely associated with the microbes as described in this review. In mice, the infection or colonization of microbes in the alimentary 
CONTROL

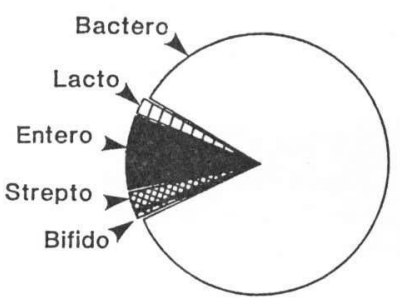

GA1

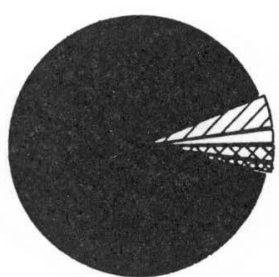

FGA1

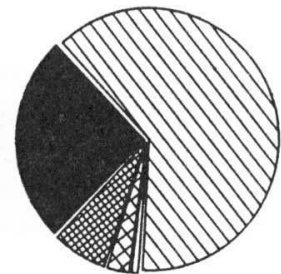

Fig. 5. Composition of the bacteria recovered from the asialo GM1 (GA1)- and the fucosyl asialo GM1 (FGA1)-coated plastic plate, in comparison with the original cecal bacterial suspension (Control). The data at the bacterial concentration $(\times 25$ dilution of the original suspension) in Fig. 4 were recalculated. Bactero, Lacto, Entero, Bifido, and Strepto represent Bacteroides, Lactobacilli, Enterobacteriaceae, Bifidobacterium, and Streptococci, respectively.

tract greatly affect the glycolipid structure. This step might be mediated via a proteinaceous soluble factor present in the intestinal tissue. On the other hand, the glycolipids may play a role as attachment site for the microbes from the results of in vitro experiments concerning the binding of the microbes to the glycolipids. In mice, Enterobacteriaceae was shown to attach to asialo GM1 to some extent. However, Enterobacteriaceae lost its affinity to fucosyl asialo GM1. Enterobacteriaceae contamination of germfree mice induced fucosylation of asialo GM1 to a small extent. These results prompt a hypothesis that the host animal has a defense mechanism against the infection by alteration of cell-surface glycolipids. To test this hypothesis, further investigation is required.

Acknowledgments. I am deeply indebted to Ms. S. Setoyama and Ms. M. Ohara, and the animalcare staff in our institute for excellent technical assistance and for animal breeding, respectively.

\section{REFERENCES}

(1) Bjork, S., M.E. Breimer, G.C. Hansson, K.-A. Karlsson, and H. Leffler. 1987. Structure of blood group glycosphingolipids of human small intestine. J. Biol. Chem. 262: 6758-6765.

(2) Bouhours, J.-F., and R.M. Glickman. 1976. Rat intestinal glycolipids. II. Distribution and biosynthesis of glycolipids and ceramide in villus and crypt cells. Biochem. Biophys. Acta 441 : 123-133.

(3) Breimer, M.E., G.C. Hansson, K.-A. Karlsson, and H. Leffler. 1981. Blood group type glycosphingolipids from the small intestine of different animals analyzed by mass spectrometry and thin-layer chromatography. A note on species diversity. J. Biochem. 90: 589-609.

(4) Breimer, M.E., G.C. Hansson, K.-A. Karlsson, and H. Leffler. 1982. Studies on differentiating epithelial cells of rat small intestine. Alterations in the lipophilic part of glycosphingolipids during cell migration from crypt to villus tip. Biochem. Biophys. Acta 710: 415-427.

(5) Gustafsson, B.E., K.-A. Karlsson, G. Larson, T. Midtvedt, N. Stromberg, S. Teneberg, and J. Thurin. 1986. Glycosphingolipid patterns of the gastrointestinal tract and feaces of germ-free and conventional rats. J. Biol. Chem. 261: 15294-15300.

(6) Hakomori, S. 1975. Fucolipids and blood group glycolipids in normal and tumor tissue. Prog. Biochem. Pharmacol. 10: 167-196. 
(7) Hansson, G.C., K.-A. Karlsson, G. Larson, N. Stromberg, and J. Thurin. 1985. Carbohydratrespecific adhesion of bacteria to thin-layer chromatograms: a rationalized approach to the study of host cell glycolipid receptors. Anal. Biochem. 146: 158-163.

(8) Hansson, G.C., K.-A. Karlsson, and J. Thurin. 1984. Glycosphingolipid patterns of the epithelial and non-epithelial compartments of rat large intestine. Biochem. Biophys. Acta 792: 281-292.

(9) Itzkowitz, S.H., M. Yuan, Y. Fukushi, A. Palekar, P.C. Phels, A.M. Shamsuddin, B.F. Trumn, S.-I. Hakomori, and Y.S. Kim. 1986. Lewisx- and sialylated Lewisx-related antigen expression in human malignant and nonmalignant colonic tissues, Cancer Res. 46: 2627-2632.

(10) Karlsson, K.-A. 1986. Animal glycolipids as attachment sites for microbes. Chem. Phys. Lipids 42: 153-172.

(11) Kawai, K., M. Fujita, and M. Nakao. 1974. Lipid composition of two different regions of an intestinal epithelial cell membrane of mouse. Biochem. Biophys. Acta 369: 222-233.

(12) Larson, G., P. Watsfeldt, P. Falk, H. Leffler, and H. Koprowski. 1987. Fecal excretion of intestinal glycosphingolipids by new borns and young children. FEBS Lett. 214: 41-44.

(13) Larson, G., P. Falk, and L.C. Hoskins. 1988. Degradation of human intestinal glycosphingolipids by extracellular glycosidases from mucin-degrading bacteria of the human fecal flora. J. Biol. Chem. 263: 10790-10798.

(14) Leffler, H. 1988. The role of epithelial cell surface glycoconjugates in self-not-self and self-self interaction. Monogr. Allergy 24 : 25-34.

(15) Leffler, H., G.C. Hansson, and N. Stromberg. 1986. A novel sulfoglycolipid of mouse small intestine, IV3-sulfoganglioteraosylcermaide, demonstrated by negative ion fast atom bombardment mass spectrometry. J. Biol. Chem. 25: 1440-1444.

(16) Mitsuoka, T., and K. Hayakawa. 1972. The fecal flora of man: The composition of the fecal flora of different age groups. Zentralbl. Bakteriol. Hyg. I. Abt. Orig. A223: 333-349.

(17) Mitsuoka, T. 1981. A Color Atlas of Anaerobic Bacteria (in Japanese), Sobunsya, Tokyo.

(18) Sato, E., T. Uezato, M. Fujita, and K. Nishimura. 1982. Developmental profiles of glycolipids in mouse small intestine. J. Biochem. 91: 2013-2019.

(19) Smith, H.W. 1965. The development of the flora of the alimentary tract in young animals. J. Path. Bact. 90: 495-513.

(20) Suzuki, A., and T. Yamakawa. 1981. The different distribution of asialo GM1 and Forssman antigens in the small intestine of mouse demonstrated by immunofluorescence staining. $\mathrm{J}$. Biochem. 90: 1541-1544.

(21) Umesaki, Y., A. Suzuki, K. Kasama, K. Tohyama, M. Mutai, and T. Yamakawa. 1981. Presence of asialo GM1 and glucosylceramide in the intestinal mucosa of mice and induction of fucosyl sialo GM1 by conventionalization of germ-free mice. J. Biochem. 90: 1731-1738.

(22) Umesaki, Y., K. Takamizawa, and M. Ohara. 1989. Structural compositional difference in the neutral glycolipids between epithelial and nonepithelial tissue of the mouse small intestine. Biochem. Biophys. Acta 1001: 157-162.

(23) Umesaki, Y., and M. Ohara. 1989. Factors regulating the neutral glycolipids in the mouse small intestine. Biochem. Biophys. Acta 1001: 163-168.

(24) Umesaki, Y. 1984. Immunohistochemical and biochemical demonstration of the change in glycolipid composition of the intestinal epithelial cell surface in mice in relation to epithelial cell differentiation and bacterial association. J. Histochem. Cytochem. 32: 299-304.

(25) Umesaki, Y., K. Tohyama, and M. Mutai. 1981. Appearance of fucolipid after conventionalization of germ-free mice. J. Biochem. 90: 559-561.

(26) Umesaki, Y., T. Sakata, and T. Yajima. 1982. Abrupt induction of GDP-fucose: asialo GM1 fucosyltransferase in the small intestine after conventionalization of germ-free mice. Biochem. Biophys. Res. Commun. 105: 439-444.

(27) Yamakawa, T., and Y. Nagai. 1978. Glycolipids at the cell surface and their biological functions. Trends Biochem. Sci. 3: 128-131. 